\title{
KNX - STANDARD INTERNACIONAL PARA O CONTROLO DA HABITAÇÃO E EDIFÍCIOS
}

$\mathrm{Na}$ fase de conceção de qualquer edifico, os termos conforto e poupança energética assumem uma relevância crescente. Para além dos aspetos puramente arquitetónicos (orientação do edifício, isolamento térmico e acústico, as fachadas em vidro etc), a introdução de elementos tecnológicos como é o caso da domótica ou imótica, contribuem simultaneamente para controlar as despesas energéticas e proporcionam mais conforto aos utilizadores.

A análise global da distribuição dos consumos energéticos em termos de energia final, revela que $50 \%$ dos consumos incidem nos sectores que agregam a iluminação, eletrodomésticos, aquecimento e arrefecimento.

No que diz respeito a climatização que representa $25 \%$ desse consumo, a taxa tende a aumentar em resultado da cada vez maior exigência em termos de conforto térmico, razão pela qual a intervenção com sistemas de controlo inteligente revela poupanças energéticas significativas.

O KNX, standard internacional para o controlo de habitações e edifícios, cumpre com os requisitos dos standards europeus, CENELEC 5009 e CEN EN 13321-1. Sendo vários os fabricantes que desenvolvem soluções em KNX, os diversos intervenientes num projeto (arquiteto, instalador, projetista e utilizador) sentem confiança acrescida neste tipo de solução.

O KNX combina especialidades que eram habitualmente controladas separadamente:

- Iluminação

- Estores

- Aquecimento/Ar Condicionado/Ventilação

- Centro meteorológico

- Controlo temporizado

- Monitorização e sistema de alarme

- Gestão do edifício

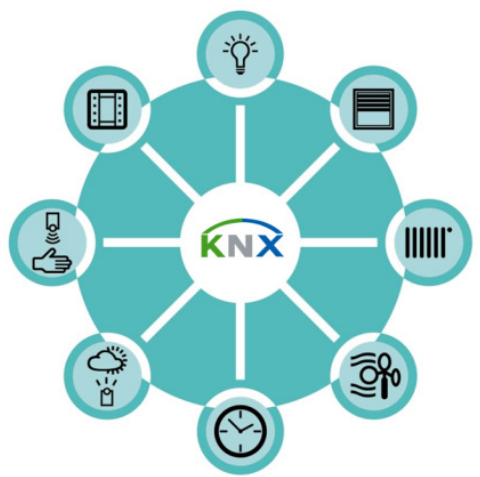

Numa solução convencional, a flexibilidade é reduzida, uma vez que existem muitas linhas separadas. Observando o esquema elétrico abaixo, é possível compreender a flexibilidade associada a tecnologia KNX.

A solução convencional: muitas linhas separadas, pouca flexibilidade.

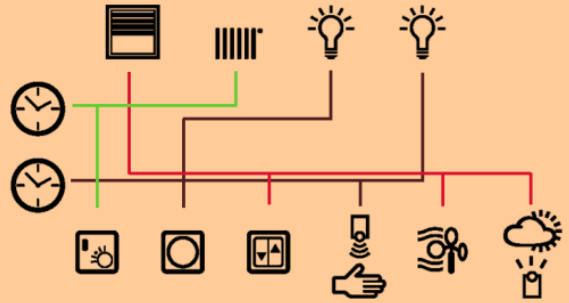

$\rightarrow$ As soluções convencionais são facilmente dominadas pelas suas limitações.

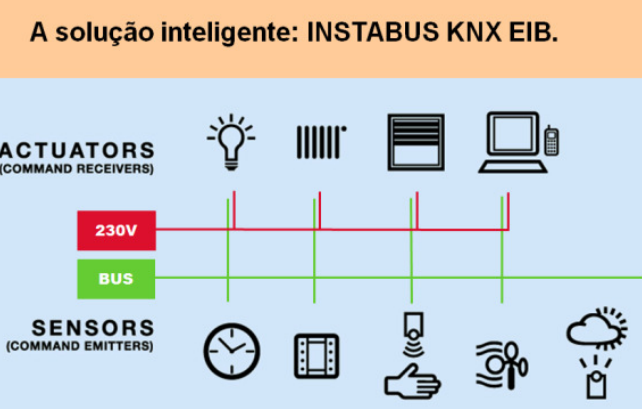

O KNX EIB abre um leque de possibilidades quase ilimitado. 


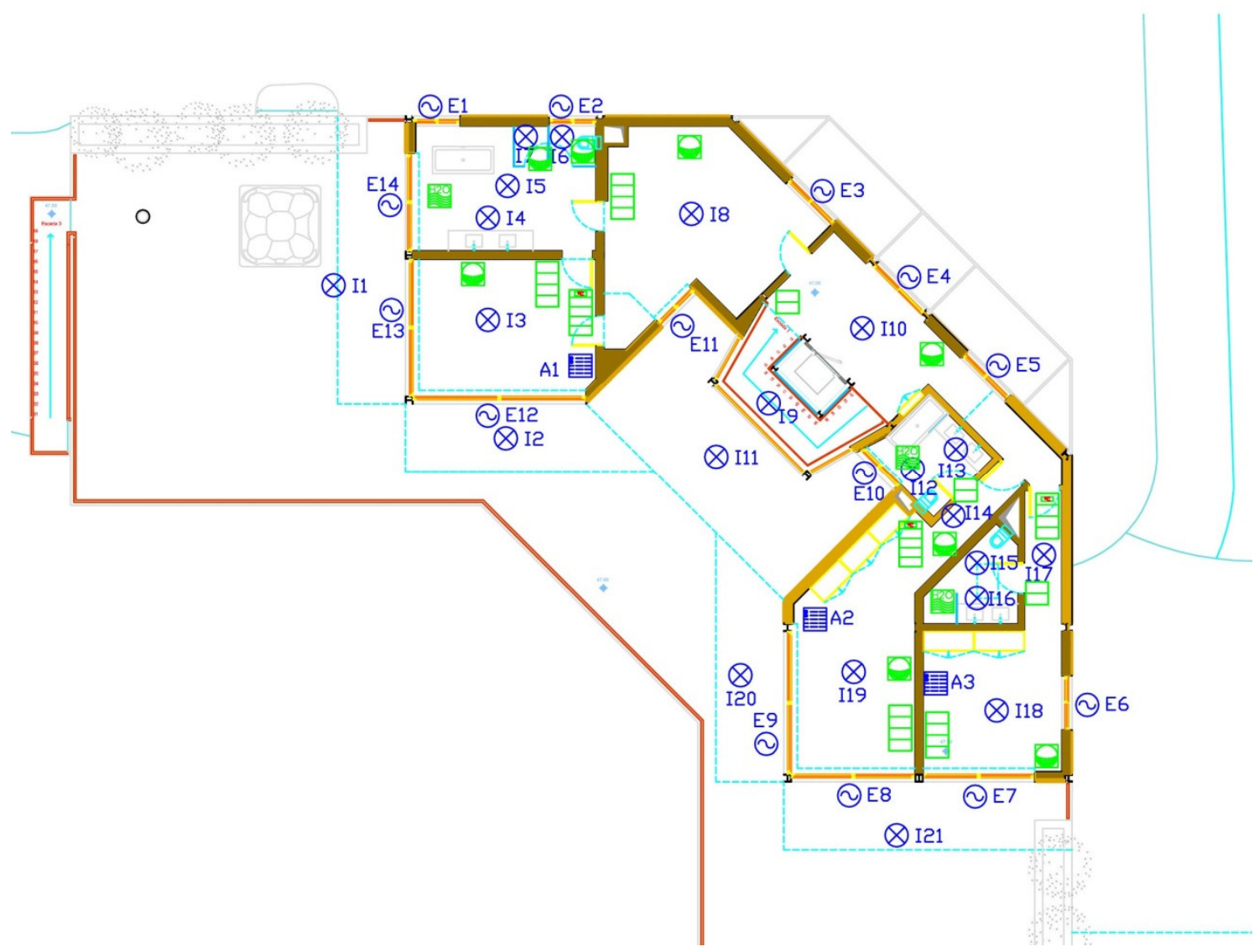

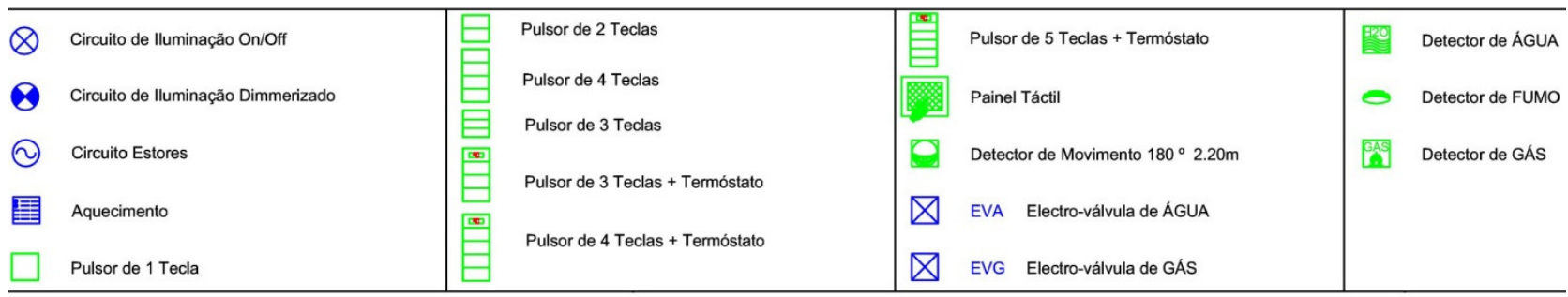

No projeto da moradia aqui retratado, o sistema KNX permite o controlo da iluminação (on/off), o controlo dos estores, o controlo da temperatura, a segurança (intrusão, inundação, incêndio e monóxido de carbono), local e central através de um painel táctil (com servidor IP KNX).

Através dos pulsores KNX é possível controlar cada um dos estores, pontos de iluminação, a temperatura de forma manual e independente, ou comandar esses equipamentos utilizando o conceito de cenários (conjunto de ações prédefinidas acionadas a determinadas teclas).
Deste modo, e a título de exemplo, será possível definir uma tecla para desligar toda a iluminação da habitação (ou parte dela), e outra tecla para abrir/fechar todos os estores.

É possível combinar numa única unidade quatro funções instabus KNX: termóstato com visor informativo, botão de pressão e temporizador. Os cenários de iluminação e outras aplicações podem ser facilmente definidos à medida das suas necessidades, com um software tão simples que qualquer pessoa o poderá fazer. 
O sistema de segurança foi concebido para proporcionar a máxima segurança com o mínimo de intervenção humana e uma integração total com o sistema KNX, contemplando:

- Segurança contra intrusão e segurança 24 horas (fumo, água, e gás);

- Comunicação telefónica de ocorrência de eventos através de mensagens de voz;

- Comando remoto por telefone através de comandos tonais (DTMF) tanto de segurança como da domótica;

- Integração funcional total com o sistema KNX, permitindo obter informação de estados num painel táctil.

- Utilização de detetores de movimento KNX nas zonas de circulação para a função alarme (quando ativo);
Neste projeto considerou-se a central de segurança KNX, comunicador telefónico, sirene exterior e interior, intrusão (detetores de movimento), inundação (sondas), e incêndio (detetores de fumo).

O controlo de todos os componentes proporciona um excelente nível de conforto e uma poupança energética que, decerto favorecerá a amortização da instalação num curto período de tempo, para além de contribuir para que a moradia seja energeticamente ecológica.

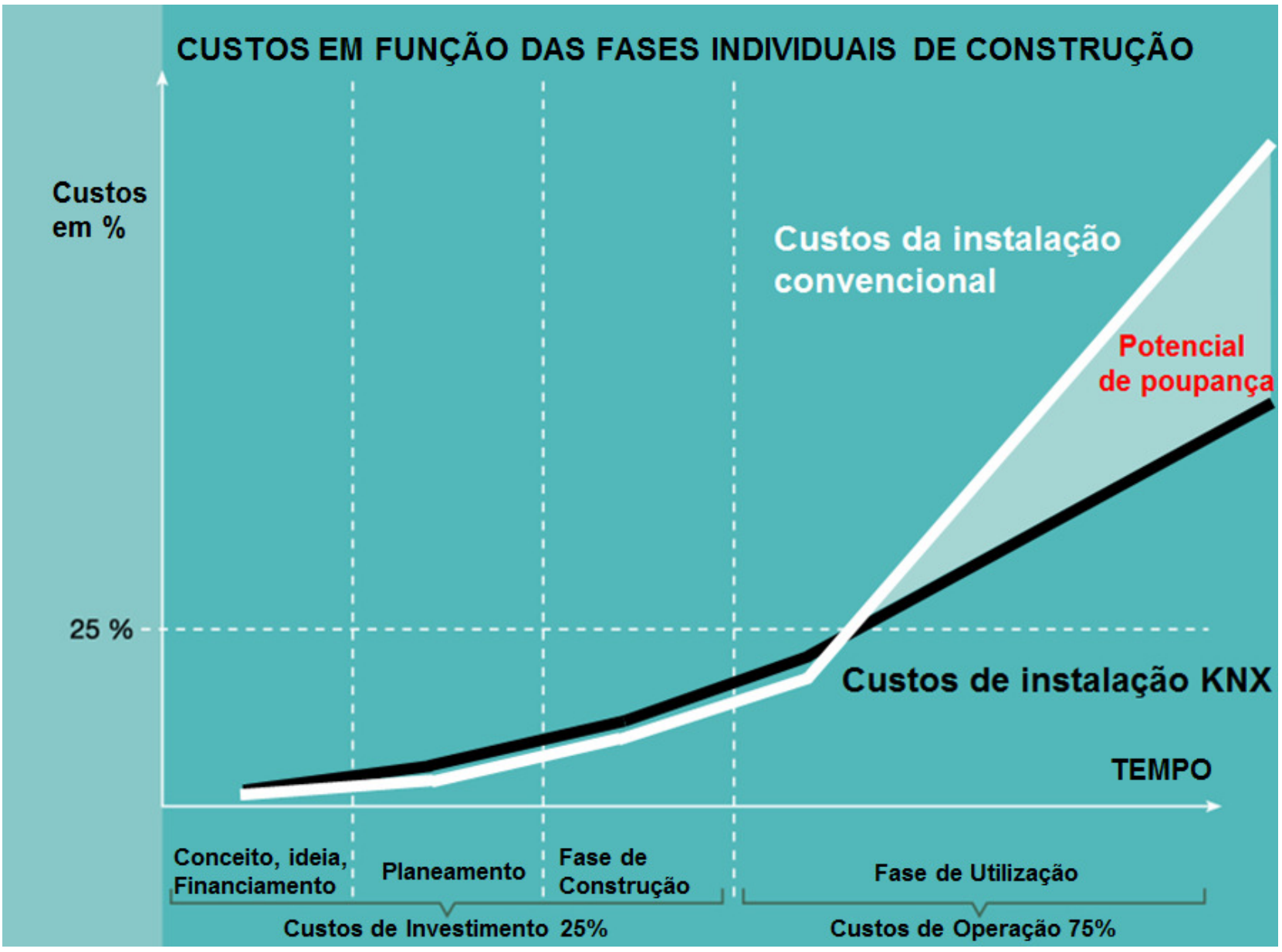

